\title{
APPLICATION OF CONDUCTIVE ADHESIVES IN MICROCIRCUITS FOR “LONG-LIFE” EQUIPMENT
}

\author{
C. W. L. KOORING and D. RIPHAGEN \\ Philips' Telecommunicatie Industrie B.V., P.O. Box 18, 1270 AA Huizen, Netherlands
}

(Received June 11, 1979)

\begin{abstract}
The results of a study of the application of conductive adhesives for attaching semiconductor chips to thin film Au conductors is presented.

The study concentrates on measuring the stability of the electrical conductivity of adhesive bonds for semiconductor chips.

Four types of conductive bonding agents and two types of semiconductor back metallization were tested at raised temperatures for up to 10,000 hours.
\end{abstract}

\section{INTRODUCTION}

The use of polymer adhesives for high-reliability microcircuit application is a radical change in electronic packaging. This new approach prompted Philips' Telecommunicatie Industrie to conduct research programs to evaluate adhesives for use in hybrid microcircuits employed in telephone equipment (low current application).

This paper presents the results of a study of the application of conductive adhesives for attaching semiconductor chips to thin film Au conductors. The study concentrates on measuring the stability of the electrical conductivity of adhesive bonds for semiconductor chips.

Four conductive adhesives were selected for testing: three types of Ag-filled epoxy adhesives and one type of Au-filled epoxy adhesive. A problem associated with the use of conductive adhesives for attaching semiconductor chips is the necessity of low contact resistance between the adhesive and, both $\mathrm{N}$ and $\mathrm{P}$, low resistivity silicon.

For this study the following chip contact metallizations were tested:

- AsAu sintered for $\mathrm{N}$-doped $\mathrm{Si}$, and $\mathrm{Au}$ sintered for P-doped Si. These two form the standard metallization systems generally used for chips intended for eutectic bonding.

- Ti+Au for both $\mathrm{N}$ and $\mathrm{P}$ doped silicon was tested as an alternative contact metallization system.

- For recognizing any changes in the series resistance of an epoxybonded chip caused by the metallization, gold pellets were used as a reference.

The variables tested in this program are listed in Table I

TABLE I

Variables tested

\begin{tabular}{|c|c|c|c|c|c|c|c|c|c|c|c|c|c|c|c|c|}
\hline & \multicolumn{4}{|c|}{$\begin{array}{l}\text { AsAu on } \\
\text { N-silicon }\end{array}$} & \multicolumn{2}{|c|}{$\begin{array}{l}\text { Au on } \\
\text { P-silicon }\end{array}$} & \multicolumn{4}{|c|}{$\begin{array}{c}\text { Components } \\
\text { Silicon chips with: } \\
\mathrm{Ti}+\mathrm{Au} \text { on } \\
\mathrm{N} \text {-silicon }\end{array}$} & \multicolumn{3}{|c|}{$\begin{array}{l}\mathrm{Ti}+\mathrm{Au} \text { on } \\
\text { P-silicon }\end{array}$} & \multicolumn{3}{|c|}{ Au pellets } \\
\hline & $\begin{array}{l}\text { Test } \\
\text { temp. }\end{array}$ & $\begin{array}{l}100 \\
{ }^{\circ} \mathrm{C}\end{array}$ & $\begin{array}{l}125 \\
{ }^{\circ} \mathrm{C}\end{array}$ & $\begin{array}{l}150 \\
{ }^{\circ} \mathrm{C}\end{array}$ & $\begin{array}{l}100 \\
{ }^{\circ} \mathrm{C}\end{array}$ & $\begin{array}{l}125 \\
{ }^{\circ} \mathrm{C}\end{array}$ & $\begin{array}{l}150 \\
{ }^{\circ} \mathrm{C}\end{array}$ & $\begin{array}{l}100 \\
{ }^{\circ} \mathrm{C}\end{array}$ & $\begin{array}{l}125 \\
{ }^{\circ} \mathrm{C}\end{array}$ & $\begin{array}{l}150 \\
{ }^{\circ} \mathrm{C}\end{array}$ & $\begin{array}{l}100 \\
{ }^{\circ} \mathrm{C}\end{array}$ & $\begin{array}{l}125 \\
{ }^{\circ} \mathrm{C}\end{array}$ & $\begin{array}{l}150 \\
{ }^{\circ} \mathrm{C}\end{array}$ & $\begin{array}{l}100 \\
{ }^{\circ} \mathrm{C}\end{array}$ & $\begin{array}{l}125 \\
{ }^{\circ} \mathrm{C}\end{array}$ & $\begin{array}{l}150 \\
{ }^{\circ} \mathrm{C}\end{array}$ \\
\hline \multirow{4}{*}{ 窟 } & A & $\mathrm{x}$ & $\mathrm{x}$ & $\mathrm{x}$ & $\mathrm{x}$ & $\mathrm{x}$ & $\mathrm{x}$ & & & & & & & $\mathrm{x}$ & $\mathrm{x}$ & $\mathbf{x}$ \\
\hline & B & & $\mathrm{x}$ & & & $\mathbf{x}$ & & & & & & & & & $\mathrm{x}$ & \\
\hline & C & $\mathrm{x}$ & $\mathrm{x}$ & $\mathrm{x}$ & $\mathbf{x}$ & $\mathrm{x}$ & $\mathrm{x}$ & $x$ & $\mathrm{x}$ & $\mathrm{x}$ & $x$ & $\mathbf{x}$ & $x$ & $\mathrm{x}$ & $\mathrm{x}$ & $\mathrm{x}$ \\
\hline & D & & $\mathbf{x}$ & & & $\mathrm{x}$ & & $\mathrm{x}$ & $\mathrm{x}$ & $\mathrm{x}$ & $\mathrm{x}$ & $\mathrm{x}$ & $\mathrm{x}$ & $\mathrm{x}$ & $\mathrm{x}$ & $\mathrm{x}$ \\
\hline
\end{tabular}

Note: Ni back metallization has not been tested because this metallization cannot be used for transistors with Au bonding pads. 


\section{DEVICE TESTED}

In most publications dealing with the study of the electrical conductivity of metal-filled adhesives the resistance of a conductor track made from the adhesive under test is measured. To be able to measure the resistance under realistic conditions, a test module was designed for this program, see Figure 1.

The test module consists of 2 thin film circuits with a conductor pattern of $12 \mu \mathrm{m}$ annealed electrodeposited gold.
Using the adhesive under test, $34 \mathrm{Si}$ chips were bonded to the outer rows of mounting pads and $18 \mathrm{Au}$ pellets were bonded to the inner rows of mounting pads. The adhesives were applied by screen printing (screen 200 mesh).

The cure schedule for the various adhesives is shown in Table II.

To enable the measurement of individual adhesive joints, a maximum number of connections was made between bonding pads and package leads.

To reduce series resistance and to exclude semiconductor properties, special Si chips without

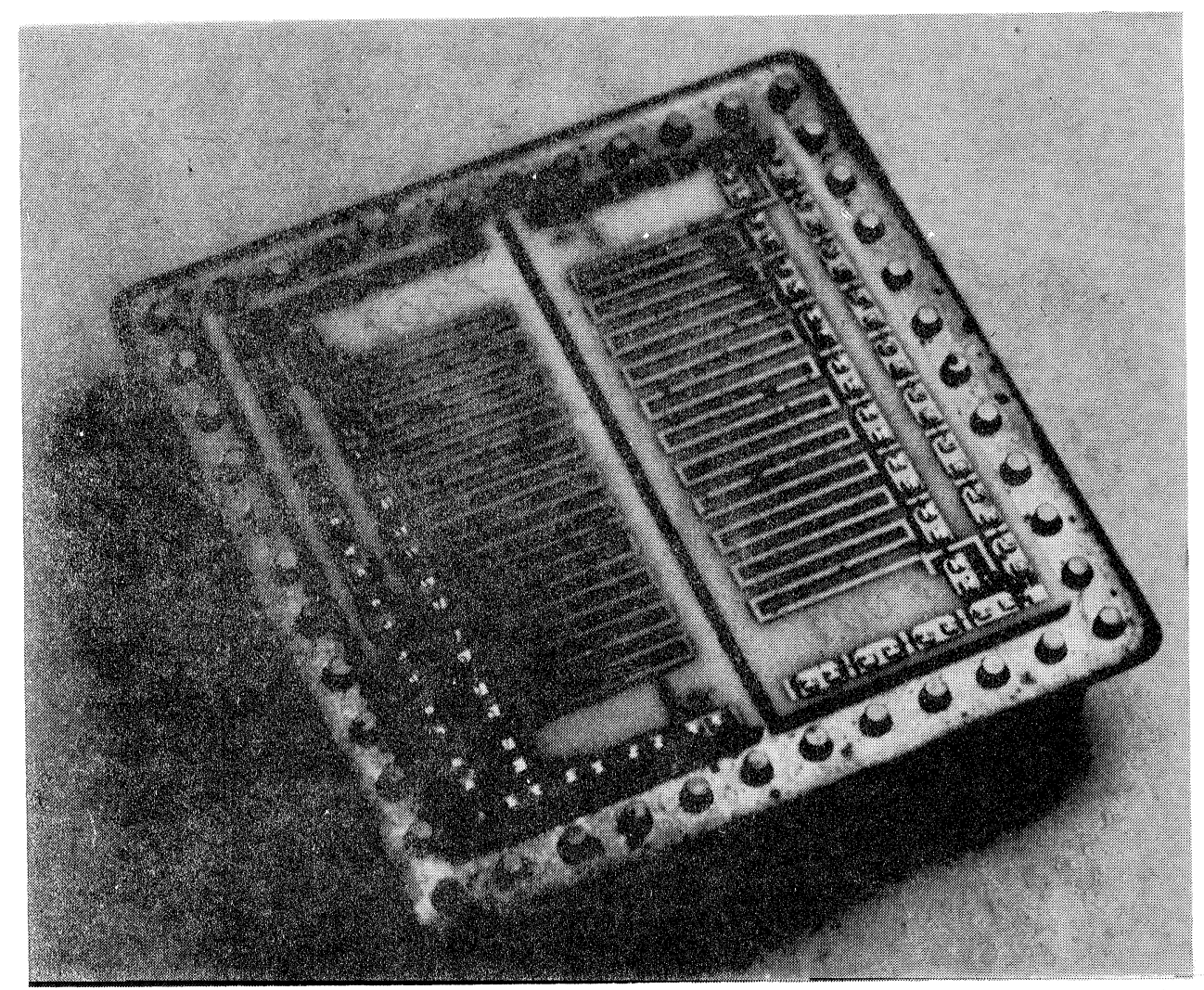

FIGURE 1 Device tested

TABLE II

Cure schedule of tested adhesives

\begin{tabular}{lllll}
\hline Adhesive & Type & Cure temp. & Cure time & Notes \\
\hline A & 1 component Ag-filled epoxy resin & $150^{\circ} \mathrm{C}$ & $75 \mathrm{~min}$. & \\
B & 1 component Ag-filled epoxy resin & $150^{\circ} \mathrm{C}$ & 75 min. & \\
C & 2 components Ag-filled epoxy resin & $150^{\circ} \mathrm{C}$ & 10 min. & batch 6 \\
D & 1 component Au-filled epoxy resin & $125^{\circ} \mathrm{C}$ & 75 min. & batch 4,5 \\
\hline
\end{tabular}


TABLE III

Chips tested

\begin{tabular}{lrllll}
\hline Chip & $\begin{array}{l}\text { Chip } \\
\text { tesistivity }\end{array}$ & $\begin{array}{l}\text { Chip dims } \\
\mathrm{mm}\end{array}$ & $\begin{array}{l}\text { Bonding pad } \\
\text { dia. }(\mu \mathrm{m})\end{array}$ & $\begin{array}{l}\text { Top } \\
\text { metallization }\end{array}$ & $\begin{array}{l}\text { Back } \\
\text { metallization }\end{array}$ \\
\hline N doped Si & $8 \mathrm{~m} \Omega \mathrm{cm}$ & $.5 \times .5 \times .12$ & $\emptyset 200$ & Ti-Pt-Au & AsAu,sintered \\
P doped Si & $18 \mathrm{~m} \Omega \mathrm{cm}$ & $.5 \times .5 \times .12$ & $\emptyset 300$ & PtSi-Ti-Pt-Au & Au,sintered \\
N doped Si & $5 \mathrm{~m} \Omega \mathrm{cm}$ & $.5 \times .5 \times .12$ & $\emptyset 200$ & Ti-Pt-Au & Ti $+\mathrm{Au}$ \\
P doped Si & $35 \mathrm{~m} \Omega \mathrm{cm}$ & $.5 \times .5 \times .12$ & $\emptyset 300$ & PtSi-Ti-Pt-Au & Ti $+\mathrm{Au}$ \\
Au pellets $99.99 \% \mathrm{Au}$ & $.5 \times .5 \times .15$ & - & - & - \\
\hline
\end{tabular}

epitaxy and with low Si bulk resistivity were made for this program by Elcoma, Nijmegen. The data of the chips tested are listed in Table III.

The components were interconnected by annealed gold wire, bonded with Hughes TC bonder HPB 360 (thermocompression bonder with pulse-heated capillary), the circuit was preheated to $130^{\circ} \mathrm{C}$ and the capillary temperature was $350^{\circ} \mathrm{C}(1.5 \mathrm{sec}$.).

The assembled circuits were secured in a metal plug-in package with a glass-fabric supported epoxy adhesive. The cure schedule was $2 \mathrm{hrs}$ at $125^{\circ} \mathrm{C}$.

The encapsulations were filled with $\mathrm{N}_{2}$ and sealed by soldering (leakrate $\leqslant 5 \cdot 10^{-7}$ atm. cc/sec.).

\section{EVALUATION CRITERIA AND MEASURING METHOD}

To determine the stability of the adhesive joints, the series resistance of the bonded components was measured.

When resistance drift of the adhesive joints was observed, measurements were carried out on parts of the outer rows of adhesive joints to check whether the observed drift was caused by one adhesive joint or equally distributed over the series-conducted joints. The measurements were carried out with the aid of an HP Multi-Function meter 3450B, which is a 5-digit integrating digital Volt/Ohm meter with a specified accuracy $\pm(0.01 \%$ of reading $+0.01 \mathrm{ohm})$. The design of the test module permits a Kelvin measurement, so that the influence of the lead resistance on the measuring result can be avoided. The signal current was $1 \mathrm{~mA}$. All measurements were carried out at an ambient temperature of $21^{\circ} \mathrm{C} \pm 2^{\circ} \mathrm{C}$. To avoid the influence of thermovoltages in the measuring set-up, the resistance was measured twice in short succession, with different current source polarities.

One module of each type was not subjected to tests but was used as a reference. Immediately before or after measuring the resistance of the test modules of one type, the reference module was measured. When the measuring values of the test modules were corrected for the deviation of the reference modules, an accuracy $\leqslant 5$ mohm was achieved.

\section{TESTS AND TEST RESULTS}

\subsection{Tests}

To determine the stability of the electrical conductivity of the adhesive bonds of semiconductor chips as a function of time and temperature, the test modules were tested as per IEC 68-2-2, test Ba: dry heat test.

To get some understanding of the temperature dependence of adhesive bonds, three test temperatures were chosen, viz. $100^{\circ} \mathrm{C}, 125^{\circ} \mathrm{C}$ and $150^{\circ} \mathrm{C}$ (a list of the variables tested in this program is given in Table I).

\subsection{Test Results}

4.2.1. Adhesives For comparing various epoxy compounds tested, only the test results from the adhesive-bonded Au pellets were used in order to exclude the influence of the contact metallization. The test results of the adhesive-bonded Au pellets are shown in Table IV and are given per batch of test modules manufactured at the same time.

The spread in the mean 0-hour batch values per pellet is caused by the tolerances of the sheet resistance (thickness) of the substrate metallization and the bonding method ( 1 or 2 wires). The resistance of a conductive adhesive bond $(\mathrm{Au}-\mathrm{Au})$ derived from the 0 -hour values of the test modules was found to be $0.5 \mathrm{mohm}$ at most and no significant difference between the 4 tested adhesives was found. The measured increase of the contact resistance (maximum $18 \mathrm{mohm}$ ) is of minor importance for present-day applications. The failure mode which 


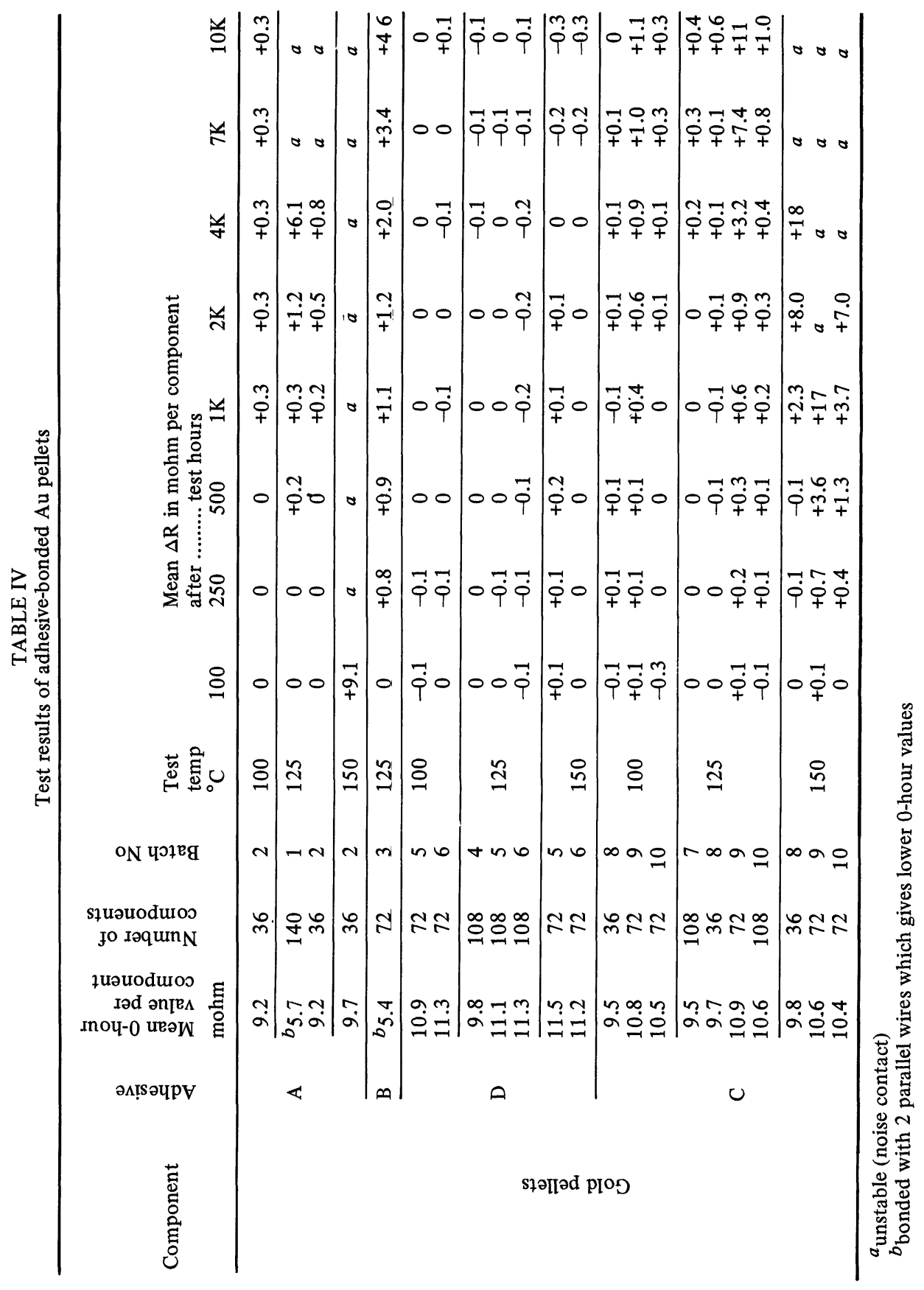


governs end of life was found to be the instability of the electrical resistance.

Discussion of the test results:

For long-term high-reliability applications, adhesive $\mathrm{D}$ is obviously the most suitable one. Because this Au-filled adhesive can stand testing at $150^{\circ} \mathrm{C}$, it is suitable for hybrid micro-electronic circuits of quality level B-1 as laid down in MILHDBK-217B.

Of the tested Ag-filled epoxy compounds, both adhesives $\mathrm{B}$ and $\mathrm{C}$ give good results at $125^{\circ} \mathrm{C}$. The spread observed in the test results of the type $\mathrm{C}$ adhesive is probably caused by tolerances in the weighing and mixing process of this two-component adhesive. Measurements on parts of the outer rows of adhesive joints demonstrated that the observed drift was distributed over the series-connected joints.

To exclude any detrimental influence of the bonding technique used for the top contact, a number of bondings were made with an ultrasonic gold ball bonder (KS 472). No difference in test results was observed.

4.2.2 Chip metallizations. In the test results the influences of the adhesives and of the chip metallizations have been added up. Because the results obtained from the adhesive bonded Au pellets showed adhesive $\mathrm{D}$ to give a stable contact resistance in the tested contact metallization combinations, the results of the chips bonded with adhesive $D$ are the most interesting. They are shown in Table V.

The tables show 3 salient points.

1) The contact resistance of P-doped chips with sintered $\mathrm{Au}$ coating becomes unstable after 7000 hours at $125^{\circ} \mathrm{C}$.

2) The contact resistance of $\mathrm{N}$-doped chips with sintered AsAu coating increases considerably after 10,000 hours at $125^{\circ} \mathrm{C}$ and is expected to become unstable after that time.

3) $\mathrm{Ti}+\mathrm{Au}$ chip metallization gives better results a resistance increase was observed at $125^{\circ} \mathrm{C}$. Instability was observed after 5000 and 7000 hours at $150^{\circ} \mathrm{C}$ for respectively P-doped and N-doped chips.

Discussion of the test results:

One of the problems that arise when evaluating a chip metallization system is the quality of the contact resistance between the metallization and both $\mathrm{N}$ and $\mathrm{P}$-doped silicon. Moreover, the quality of the contact resistance depends on the impurity concentration, particularly with P-doped silicon. To get some understanding of the phenomena of the increase of the

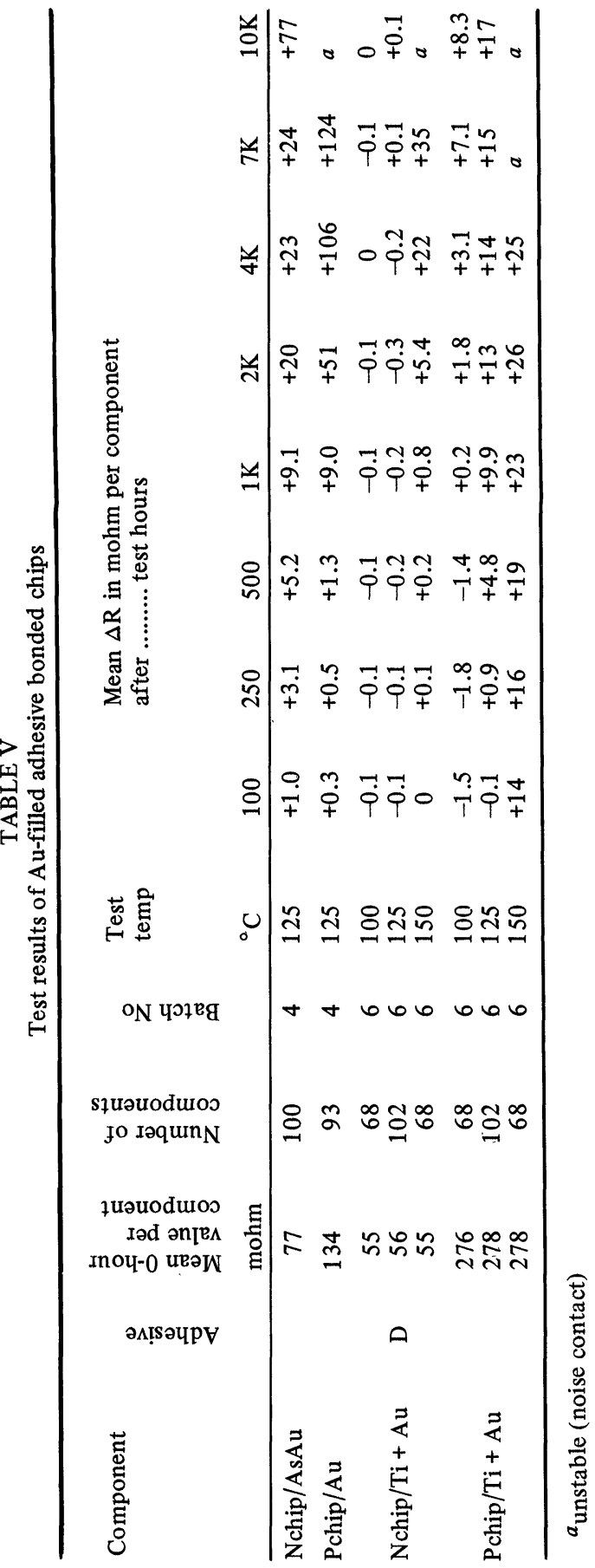




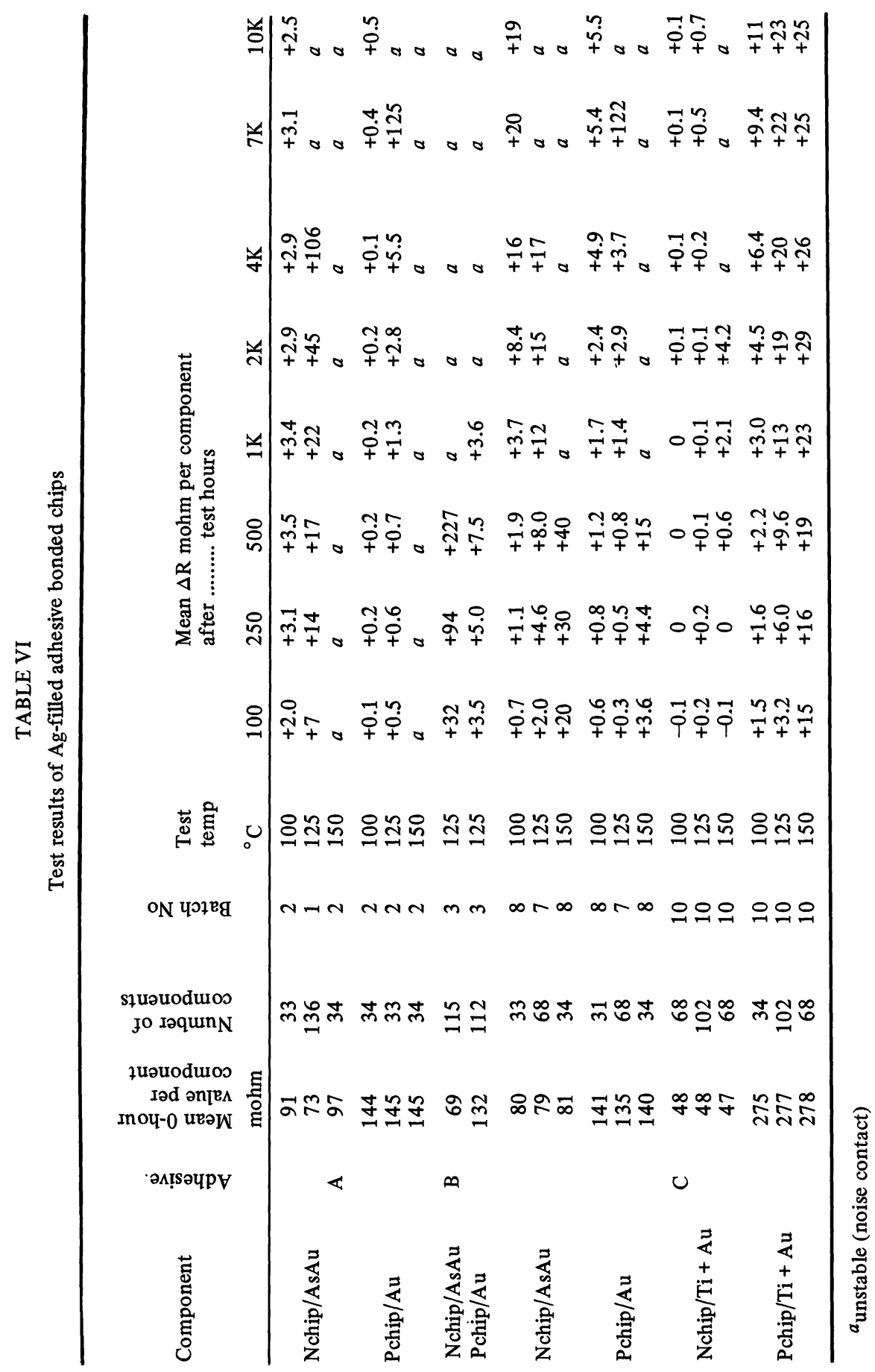


contact resistance, we opened the test modules of batch No. 4 after the 10,000-hours measurement.

The chips were prized off and the force necessary to do so showed that the adhesive strength had not significantly degraded. Most chips were severely damaged by lifting. For both $\mathrm{N}$ and P-doped chips with sintered $\mathrm{AsAu}$ and $\mathrm{Au}$, the fractures occurred more or less at the silicon-metallization interface. As the 0-hour point the fracture always occurs at the metallization-epoxy interface, it may be concluded that the adherence of the back metallization has degraded as a result of testing at $125^{\circ} \mathrm{C}$ for 10,000 hours.

The observations, combined with the results of the Au-pellets, demonstrate that the observed resistance increase is a property of semiconductors, and this is beyond the scope of this study. In our opinion, the subject of stability of the contact resistance has to be studied by the semiconductor manufacturer(s) prior to introducing a standard metallization intended for adhesive bonding. The results of testing the various Ag-filled adhesive $\mathrm{Si}$ chip combinations are shown in Table VI. The
Table shows that the adhesive behaviour dominates and that for the Ag-filled adhesive-bonded Si chips instability (noise contact) is the failure mechanism which causes end of life.

\section{CONCLUSIONS}

Of the 4 conductive adhesives tested, only the resistance of the Au-Au bonds made by means of a $\mathrm{Au}$-filled epoxy adhesive is still stable after 10.000 hours of testing at $125^{\circ} \mathrm{C}$ and at $150^{\circ} \mathrm{C}$.

When $\mathrm{Au}$-Au bonds are made with Ag-filled adhesives, instability of the resistance (noise contact) is the failure mechanism which determines the end of life.

For $\mathrm{Si}$ chips bonded with Ag-filled adhesives, the adhesive properties in combination with the chip back metallization system determine the end of life.

$\mathrm{Ti}+\mathrm{Au}$ metallization of semiconductor chips (collector) gives the best results. This is valid for $\mathrm{Ag}$ and $\mathrm{Au}$-filled epoxy compounds. 

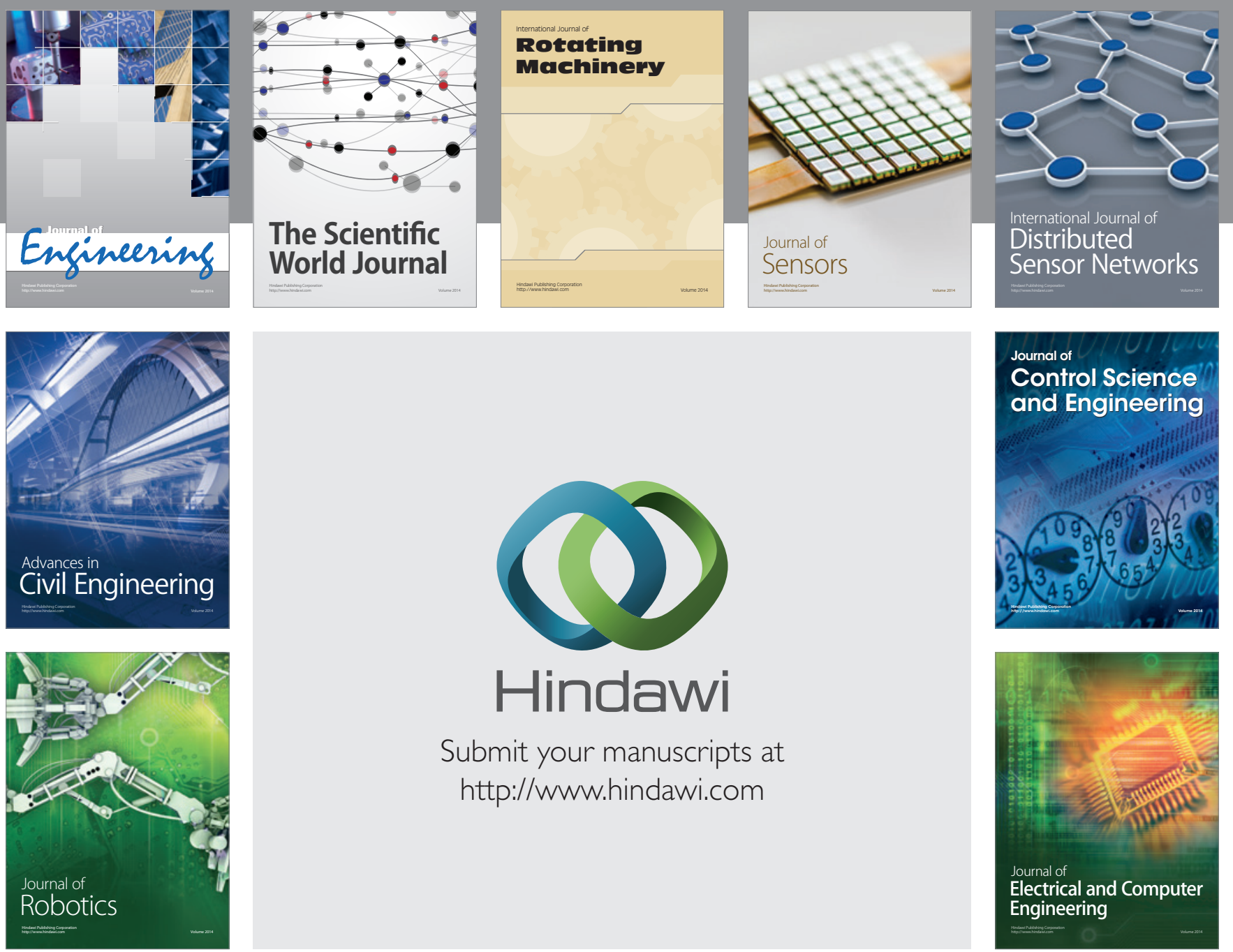

Submit your manuscripts at

http://www.hindawi.com
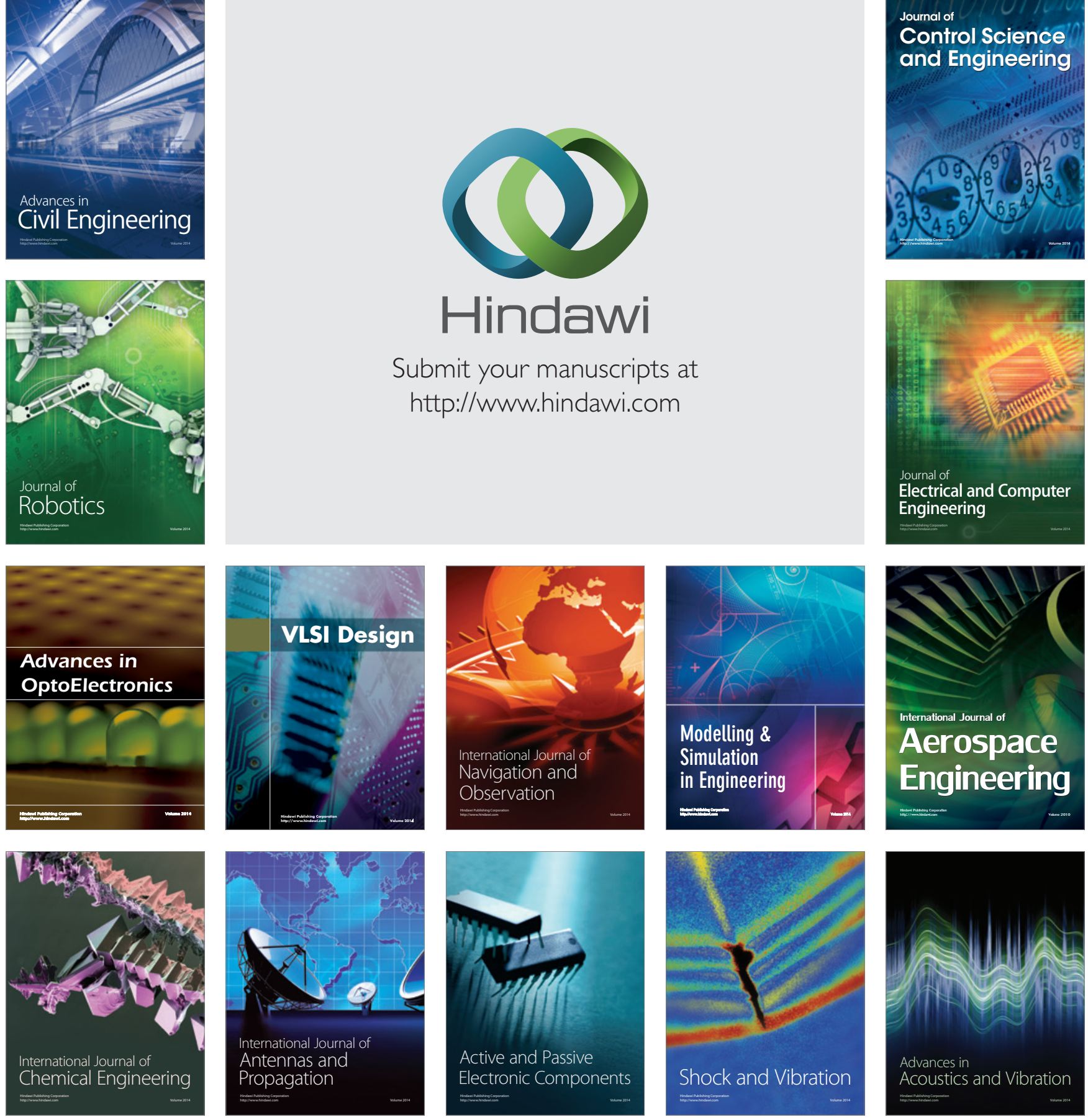